\title{
Development of Shoot Architecture of Japanese Privet in Response to Soil Moisture
}

\author{
Dilma Daniela Silva ${ }^{1}$ and Richard C. Beeson, Jr. \\ Mid-Florida Research and Education Center, Institute of Food and Agricultural Sciences, University \\ of Florida, 2725 S. Binion Road, Apopka, FL 32703; and the Environmental Horticulture Department, \\ University of Florida, Room 109, Building 68, P.O. Box 110675, Gainesville, FL 32611 \\ Michael E. Kane \\ Environmental Horticulture Department, University of Florida, Room 109, Building 68, P.O. Box \\ 110675, Gainesville, FL 32611
}

\begin{abstract}
AdDitional INDEX words. apical dominance, bud outgrowth, determinate growth, indeterminate growth, Ligustrum japonicum, preformation, water stress

ABstract. Bud outgrowth dynamics and their implications for shoot architecture were examined in japanese privet (Ligustrum japonicum) plants under well-irrigated [short irrigation cycle (SC)] and water-limitation [long irrigation cycle (LC)] conditions. New buds had limited sensitivity to dormancy, whereas preformed buds required more than one growing season to outgrow naturally. The first spring flush of shoot growth was mostly the result of lateral bud outgrowth, whereas latter flushes had prominent contributions of new apex buds. First flush terminal stems had mainly determinate growth (episodic). First flush lateral stems had increased occurrence of indeterminate growth (continuous). Water limitation influenced shoot architecture by enhancing apical dominance. Lateral branching was diminished $51 \%$ in LC plants compared with SC plants. As plants adapted to the stress imposed, indeterminate growth was triggered more often in meristematic regions of terminal buds of LC plants. In shoot flushes that occurred later in the stress treatment, old buds burst more frequently than the newly formed apex lateral buds. Plants under SC were more compact and better formed as an inverse triangle, whereas plants under $L C$ had considerably less new branches and instead had long branches that would require pruning to maintain aesthetically pleasing shapes.
\end{abstract}

Shoot branching is an important determinant of a plant's shape. Shoot branching is the process by which axillary buds develop and form new flowers or branches changing the shoot system architecture. Overall plant form is achieved by regulation of initiation and outgrowth of axillary meristems (Kerstetter and Hake, 1997). Bud outgrowth is regulated by the interaction of environmental and endogenous signals. A network of shoot and root signals that regulates branching has been proposed (Thomas and Hay, 2009). A branching signal that moves in the direction of root-to-shoot has been postulated to exist (Beveridge, 2000).

The tendency of a dormant lateral bud to outgrow is regulated by a network of variables (Waldie et al., 2010). Among the most important variables are age of the bud relative to its initiation and the zone of the stem in which the bud develops [basal vs. aerial branching (Napoli et al., 1999)]. The roles of cytokinin as a promoter and auxin as an inhibitor of lateral bud outgrowth have long been known and studied in branches with a decapitated terminal bud. However, it has been suggested that these two plant growth regulators may not be the only factors in lateral bud breakage of dormancy during undisturbed growth. Frugis et al. (2001) demonstrated that overexpression of a gene in lettuce ( $\mathrm{Lac}$ tuca sativa) associated with accumulation of specific types of cytokinins caused alterations to plant architecture, which changed from determinate to indeterminate leaf growth. Borchert (1975) observed variations of shoot growth patterns between young and mature plants of Quercus palustris.

Received for publication 14 Aug. 2014. Accepted for publication 17 Nov. 2014. ${ }^{1}$ Corresponding author. E-mail: dilma@ufl.edu.
Patterns ranged from a series of flushes characterized by determinate growth to longer flushes characterized by indeterminate growth. Branch position or geometry alone is not sufficient to account for the various growth patterns existing between species; other factors such as timing of shoot growth also affect shoot architectural pattern (Napoli et al., 1999). Depth of bud dormancy has been proposed to be related to abscisic acid (ABA) levels (Tamura et al., 1993) and water status of the bud (Arora et al., 2003). Prolonged exposure to drought can trigger ABA responses in shoot meristems such as inhibition of leaf production, growth, and development (Kuang et al., 1990; Sauter et al., 2001). Growth restrictions result in meristems losing relatively little water during water stress (Arora et al., 2003).

Napoli et al. (1999) noted that research on dormancy and shoot growth has mainly focused on herbaceous plants; thus, all concepts are not necessarily applicable to woody species. Developing a clearer understanding of bud dynamics and their type-specific contributions under undisturbed conditions is a necessary prerequisite for predicting their responses under disturbed conditions (Zhang et al., 2009). Relationships between physiological processes and environmental conditions for plant development are often confounded by variations of genetic, environmental, or ontogenetic factors (Hanson et al., 1986). The research presented here describes the natural shoot growth of clonal japanese privet grown under well-irrigated conditions and uses this as a basis for describing how this growth is changed by intermittent water limitations. This research aimed at determining how adverse and advantageous environmental factors influence whole plant episodic shoot growth in an evergreen woody species. 


\section{Material and Methods}

Growth Conditions. Two-year-old clonal japanese privet were selected based on visual uniformity from a local nursery (Jon's Nursery, Eustis, FL). On 1 Feb. 2009, one plant was transplanted into each of 24 elevated star-shaped rhizotrons (Silva and Beeson, 2011). The rhizotron had four arms and held $0.16 \mathrm{~m}^{3}$ of a commercial substrate composed of Canadian sphagnum peatmoss, processed pine bark, perlite, vermiculite, starter nutrients, wetting agents, and dolomitic limestone (Mix \#4; Conrad Fafard, Agawam, MA). Rhizotrons measured $1.76 \mathrm{~m}$ across, $0.30 \mathrm{~m}$ deep at the end of each arm, and $0.35 \mathrm{~m}$ deep in the center. Each rhizotron had $40 \mathrm{~cm}$ of a wicking material (Aquamat $^{\circledR}$ capillary system; Soleno Textiles, Laval, Quebec, Canada) extending below each arm in the center to remove excess moisture from the substrate, which maintained substrate moisture levels uniform and avoided perched water tables (Silva and Beeson, 2011).

The experiment was conducted in Apopka, FL (lat. $28.688^{\circ} \mathrm{N}$, long. $\left.86.53^{\circ} \mathrm{W}\right)$ under natural light within an open-sided greenhouse $(6.1 \times 12.3 \mathrm{~m})$ with a clear double-polyethylene roof, which diffused and reduced photosynthetic active radiation by $\approx 18 \%$. The open-sided greenhouse allowed for ambient temperature conditions while preventing precipitation from infiltrating the substrate. Irrigation was supplied independently to each rhizotron using a spray stake (Model green 22500001120; Netafim Irrigation, Fresno, CA) at the tip of each arm pointing inward. Irrigation was controlled by a data logger (CR10X; Campbell Scientific, Logan, UT) connected to a multiplexer (AM16/32B; Campbell Scientific) and two remote relay controls (SDM-CD16AC; Campbell Scientific). Substrate moisture was measured within each rhizotron using one soil moisture sensor (EC-5 $\mathrm{ECH}_{2} \mathrm{O}$ probe; Decagon Devices, Pullman, WA) per rhizotron. Sensor calibration was based on the mean of five $\mathrm{ECH}_{2} \mathrm{O}$ probes. Measurements from each probe were collected over a range of 10 substrate moisture levels determined gravimetrically based on oven-dried $\left(70{ }^{\circ} \mathrm{C}\right)$ substrate mass. A single calibration curve was developed from collected measurements (Nemali et al., 2007). At plant transplanting, the sensor was installed vertically adjacent to and half the depth of each root ball. Care was taken during sensor placement to ensure uniformity in depth and light surface compaction before settling the substrate around the sensor by adding 1.0 L of water to the surface above the sensor. Soil moisture sensors were relocated to the edge of the expanding root system every $35 \mathrm{~d}$ to compensate for root growth. Probes were pushed into the undisturbed substrate to halfway down the soil profile and centered horizontally.

All plants were irrigated daily after transplant to allow for acclimatization. Irrigation treatments began once root tips visibly reached substrate profiles of rhizotrons, $41 \mathrm{~d}$ after transplant (DAT), and then irrigation was withheld for $6 \mathrm{~d}$ before treatment initiation. Plants were fertilized by hand monthly beginning $60 \mathrm{DAT}$ with $500 \mathrm{~mL}$ of solution [3N-1P-2K (198 $\mathrm{mg} \cdot \mathrm{L}^{-1}$ nitrogen from $\mathrm{NH}_{4} \mathrm{NO}_{3}, 66 \mathrm{mg} \cdot \mathrm{L}^{-1}$ phosphorus from $\mathrm{K}_{2} \mathrm{HPO}_{4}$, and
$133 \mathrm{mg} \cdot \mathrm{L}^{-1}$ potassium from $\left.\mathrm{K}_{2} \mathrm{SO}_{4}\right)$ ] delivered to the substrate surface after an irrigation event. Treatments consisted of two irrigation frequencies, once per week for $10 \mathrm{~min}(12 \mathrm{~L}$ of water, LC) and every other day for $5 \mathrm{~min}$ (6 L of water, SC). A detailed description of water relations for this study can be found in Silva et al. (2012). Briefly, irrigation treatments had similar percent volumetric water content (\%VWC) at saturation, but significantly different minimum \%VWC. Differences in mean $\Delta \% \mathrm{VWC}\left(\% \mathrm{VWC}_{\mathrm{sat}}-\% \mathrm{VWC}_{\min }\right)$ were greater than 2 -fold (4.5 LC vs. 1.7 SC).

Rhizotrons were arranged in a completely randomized design with irrigation regime as treatments with 12 replicates each. Statistical analyses were conducted using the PROC GLM procedure. Mean separation was conducted using the Fisher's least significant difference $(P \leq 0.05)$. All statistical analyses were conducted using SAS (Version 9.1; SAS Institute, Cary, NC).

Growth Measurements. The growth of roots and shoots were monitored weekly and was not disturbed by pruning during the experiment. The number of shoot growing points (SGPs) was counted weekly throughout the experiment. A SGP was defined as a shoot tip between visual budbreak (Fig. 1C) and no unfolding of new leaves (Fig. 1A). In addition to SGP, shoot architecture parameters (length, number of leaves, bud type, and date of bud set of new branches) and number of inflorescences per plant were recorded weekly up to 138 DAT (7 July 2009).

\section{Results and Discussion}

GROWTH UNDER SHORT WET/DRY CYCLES. Japanese privet is a temperate woody shrub, native to Japan and East Asia (Ishii and Iwasaki, 2008) with opposite decussate leaves (Fig. 1D) and imbricate buds, buds with more than two scales that overlap one another (Fig. 2). At the end of each branch, a cluster of buds, referred here as apex buds, occurs (Fig. 2A and B). Apex buds are composed of one central terminal bud and two lateral buds on opposite sides. Also part of the bud cluster, there are two accessory buds for each terminal and lateral buds (Fig. 2A and B). Apex lateral buds originate from the last pair of leaves. Lateral bud refers to buds that originate from leaves older than the last pair of leaves (Fig. 2C). Each preformed terminal or lateral bud has a stem, leaf primordia, and lateral buds differentiated in previous seasons (Fig. 3B). Preformation, the differentiation of organs in a growing season before maturation with extension the next growing season, is a common characteristic
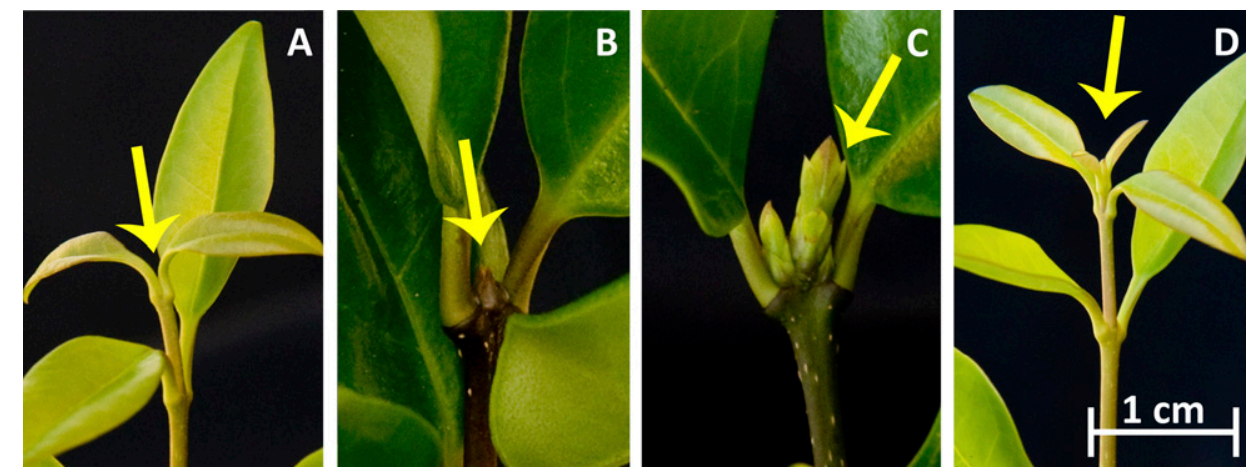

Fig. 1. Shoot tips of Ligustrum japonicum at different growth stages: (A) tip with no unfolding of leaves, (B) new bud, (C) new bud expansion, and (D) growing shoot tip. 

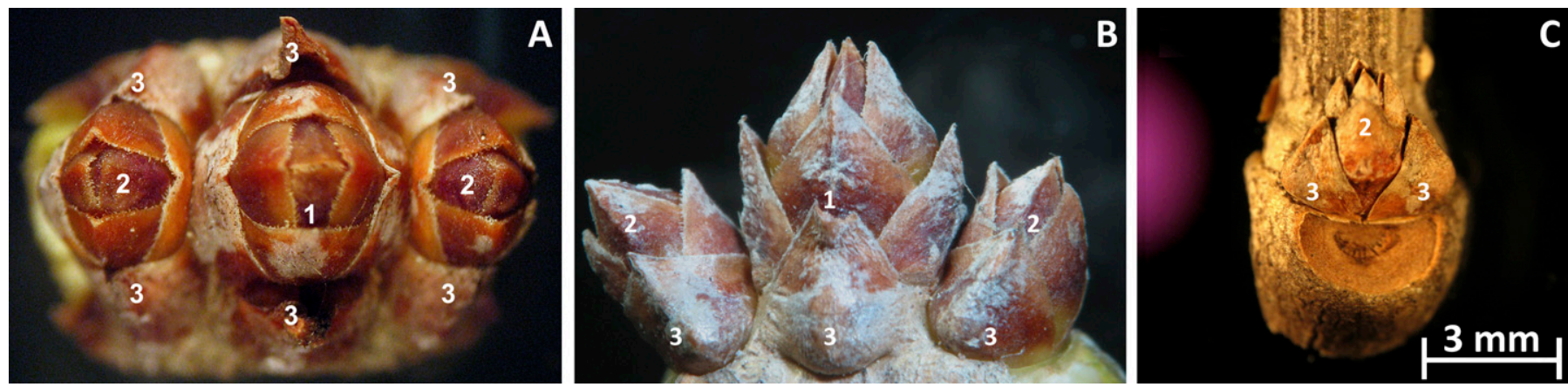

Fig. 2. Bud types of Ligustrum japonicum: (A) top view of apex buds, (B) side view of apex buds, and (C) lateral bud $(1=$ terminal bud, $2=$ lateral bud, $3=$ accessory bud).
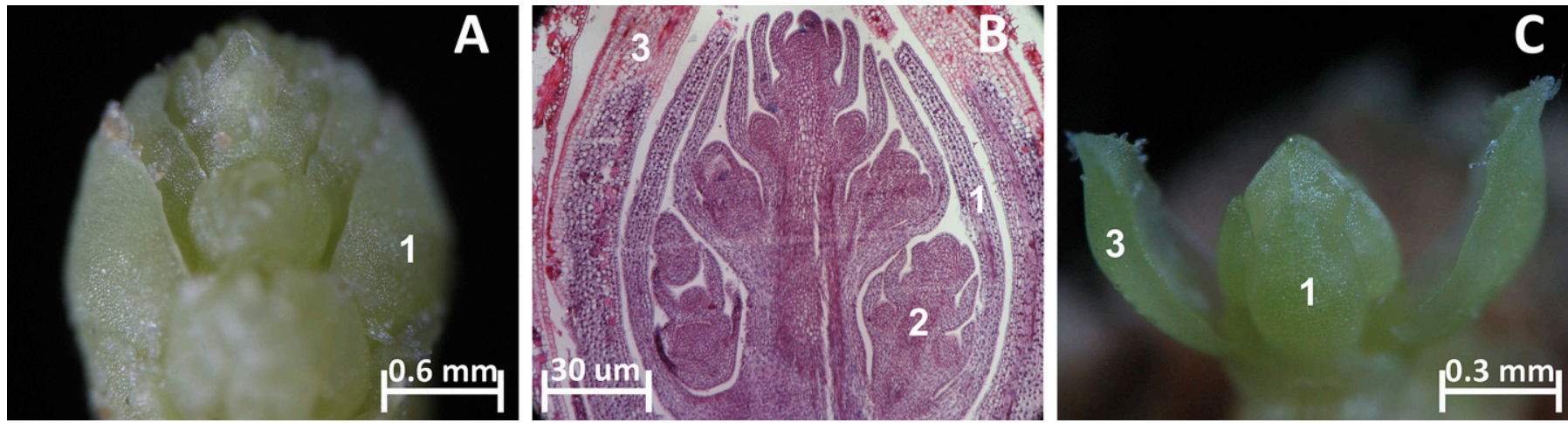

Fig. 3. Preformed buds of Ligustrum japonicum: (A) dissected terminal bud, (B) longitudinal cut of terminal bud, and $(\mathbf{C})$ dissected lateral bud $(1=$ leaf primordia, 2 = lateral bud primordia, $3=$ last pair of scales).

among temperate woody species (Meloche and Diggle, 2003; Puntieri et al., 2007; Remphrey and Powell, 1984). However, neoformation, the differentiation and extension of organs in the same growing season, is considered to be relatively uncommon among temperate woody plants (Puntieri et al., 2007).

Figure 4 is a diagrammatic representation of an averaged plant's architecture at the end of the experiment. First flush terminal stems tended to be longer than lateral for determinate stems, but not for indeterminate stems. Short cycle plants were more proportional with a good distribution of growth throughout the plant.

Although under influence of apical dominance, vegetative lateral buds of Rosa hybrida increased dry mass and developed new leaf primordia with age while still in the bud stage (Marcelis-Van Acker, 1994). Similar shoot development in the bud stage was found for japanese privet. Despite preformed lateral bud maturation during the present growing season, lateral buds located in new branches only burst the next growing season or if apical dormancy was broken. No new lateral buds outgrew during the growing season comprised by this experiment (Fig. 5). However, $7.6 \%$ of new apex lateral buds expanded to form second-flush stems, whereas $24.1 \%$ of new terminal buds formed second-flush stems (Fig. 5). New lateral buds are preformed and mature in the same growing season in which the main branch expands, while new apex lateral buds, together with new terminal buds, are formed and mature in the same growing. New apex lateral buds appear less sensitive to dormancy than preformed buds, which required more than one growing season to naturally outgrow. Any tentative effort to explain apical dominance or dormancy depth should take bud position and age into consideration. In
Quercus, branching order and age were the most important influences on bud outgrowth compared with several manipulative treatments such as defoliation and terminal bud removal (Buck-Sorlin and Bell, 2000).

Apical dominance is a term generally used to refer to inhibition of growth of lateral buds by the terminal bud (Little, 1970; Napoli et al., 1999). Although a degree of apical dominance was noted, this species appears to have weak apical dominance. Only $45.7 \%$ of total growing points originated from terminal buds (Fig. 6). Additionally, the first flush of growth was mostly the result of lateral bud outgrowth. It is important to note that lateral bud outgrowth was independent of terminal bud decapitation. Plants in this study were not pruned. Decapitation causes not only the commonly discussed plant growth regulator alterations, but also imposes stress by wounding and causes changes in xylem fluid flow and in sink strength (Napoli et al., 1999). The dormancy-released lateral buds were mostly located in the basal zone of a plant. Thus, the first flush of growth, in the beginning of spring, may be a result of an interaction of ecodormancy release with positional clues, because the terminal bud in the same branch was generally not released.

A new branch was a single stem developed from a preformed bud and its subsequent second- and third-flush shoots (Fig. 7). A terminal branch was defined as a new branch arising from a preformed terminal bud, and a lateral branch was defined as a new branch formed from a preformed lateral bud. Of the total number of new terminal branches, $54.5 \%$ had more than one flush of growth (Fig. 8), whereas fewer lateral branches (29.7\%) had more than one flush of growth. This suggests differences in sink strength between branch positions in a plant. Furthermore, $85.4 \%$ of old branches that produced new growth generated 


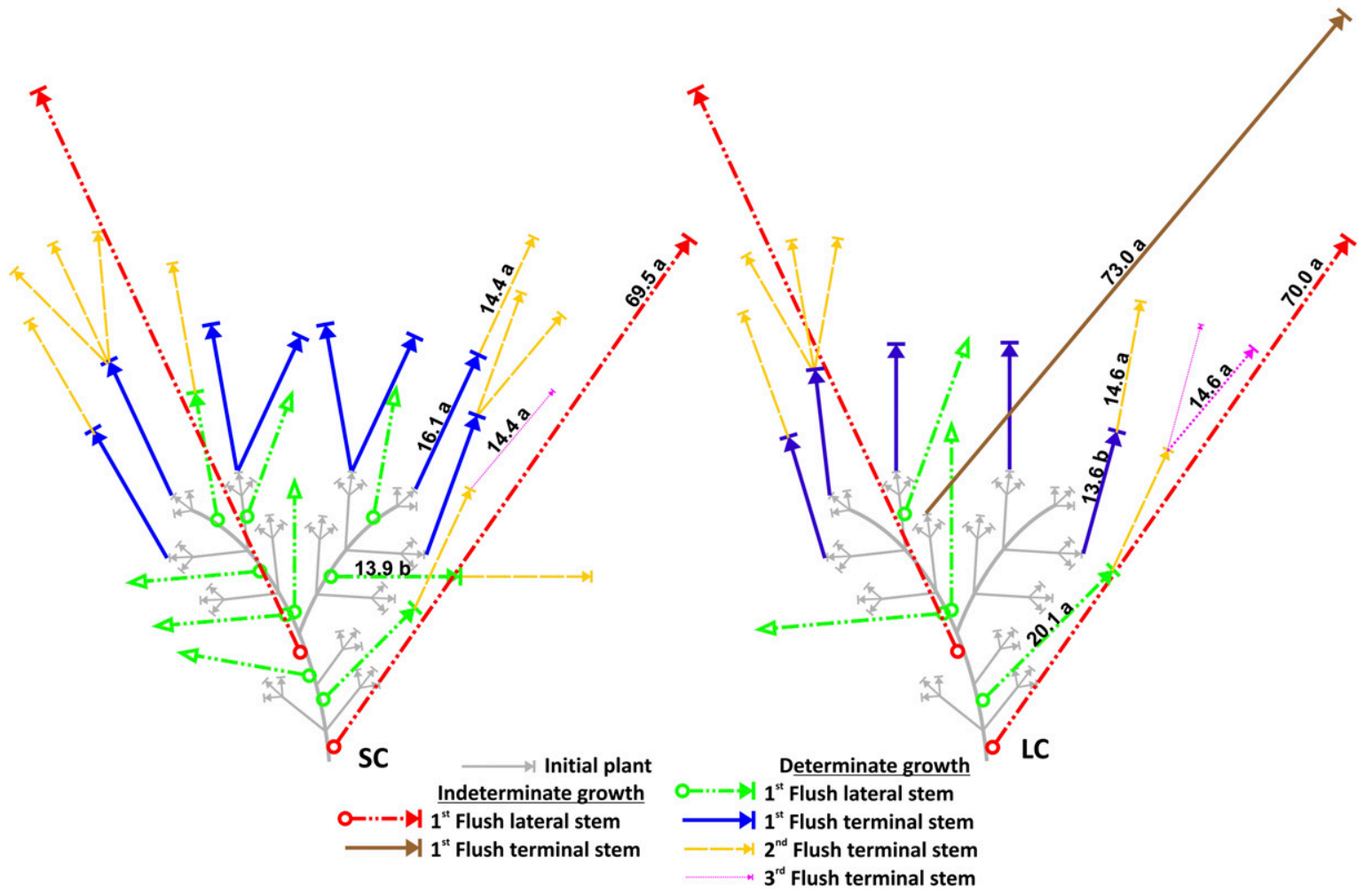

Fig. 4. Diagrammatic representation of Ligustrum japonicum architecture after treatments [short irrigation cycle (SC) and long irrigation cycle (LC)]. Numbers indicate average stem length $(\mathrm{cm})$ followed by letters indicating mean separation between treatments by Fisher's least significant difference at $P=0.05$.

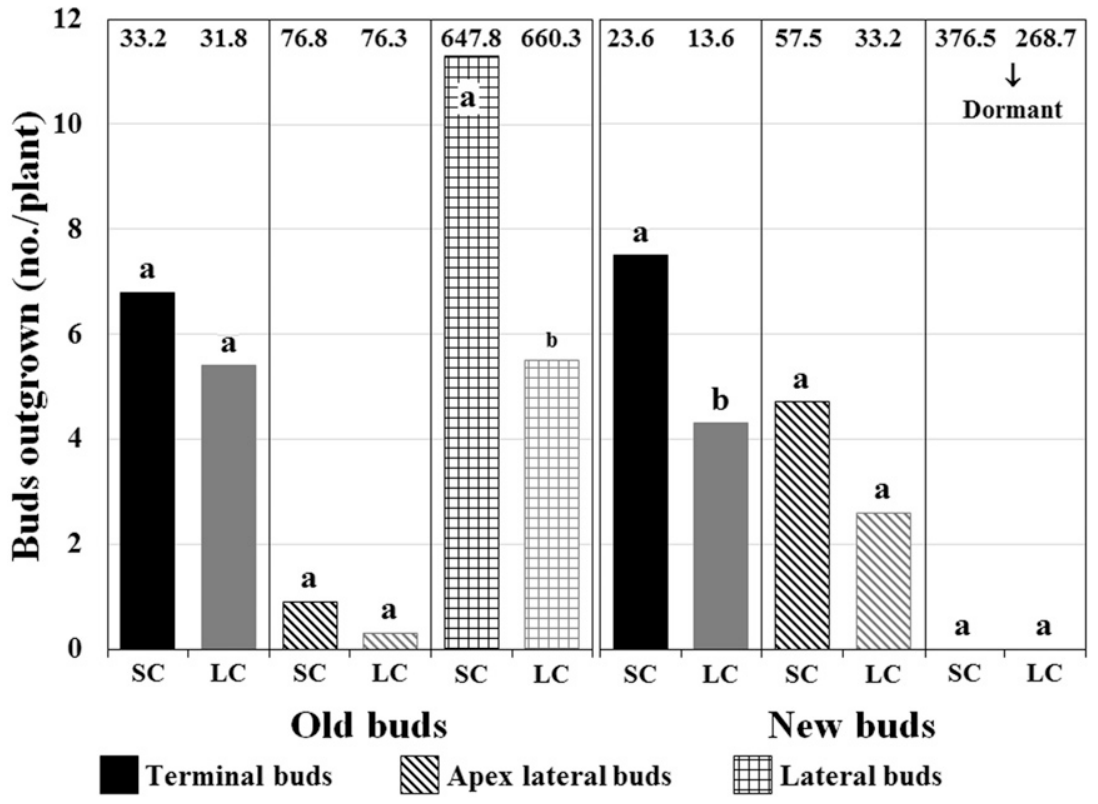

Fig. 5. Bud outgrowth per plant of Ligustrum japonicum. Numbers on top of the panels are number of dormant buds per plant [short irrigation cycle (SC), long irrigation cycle (LC)]. Letters indicate mean separation between treatments by Fisher's least significant difference at $P=0.05$. bud always produced longer stems with more leaves than a branch originated from an apex lateral bud developing by its side.

Stem final size depended on whether growth was indeterminate or determinate. Indeterminate growth occurred mostly from isolated lateral branches, which were responsible for $29.5 \%$ of all stem length in SC treatment (Fig. 11). Stems with apparent determinate growth measured on average 16.1 and $13.9 \mathrm{~cm}$ [terminal and lateral firstflush stems, respectively (Fig. 4)], whereas stems with indeterminate growth averaged 58.9 and $69.5 \mathrm{~cm}$ in length for terminal and lateral stems, respectively (Fig. 4). First-flush indeterminate terminal stems are not represented in Figure 4, because the average was only 0.3 stems $/$ plant. For some tree species, neoformation contributed more to axis formation than preformation (Costes, 2003; Guedon et al., 2006; Snowball, 1997). However, the greatest percentage of japanese privet linear shoot formation was the result of extension of preformed parts from previous growing seasons.

The number of leaves per stem and the only one new branch (Fig. 9) with the majority of lateral bud outgrowth occurring isolated (Fig. 10). Isolated outgrowth refers to a single bud outgrown from a leaf pair. In some cases, both lateral buds of the same leaf pair outgrew concurrently. Branching tended to be basal [11.1 lateral branches per plant vs. 7.7 terminal branches per plant (Figs. 4 and 8)]. The terminal internode length of determinate lateral stems were smaller than observed for determinate terminal stems and associated secondflush stems. However, there were no differences between terminal and lateral stems when growth was indeterminate (data not shown). The lower number of leaves originated by lateral buds than by terminal buds agrees with observations of 


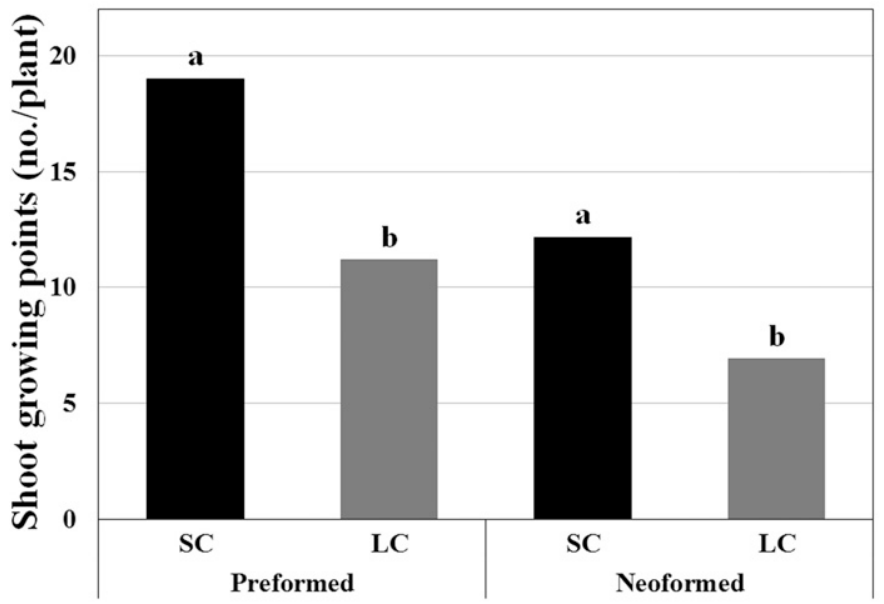

Fig. 6. Total number of shoot growing points per plant of Ligustrum japonicum at harvest [short irrigation cycle (SC), long irrigation cycle (LC)]. Letters indicate mean separation between treatments by Fisher's least significant difference at $P=0.05$.

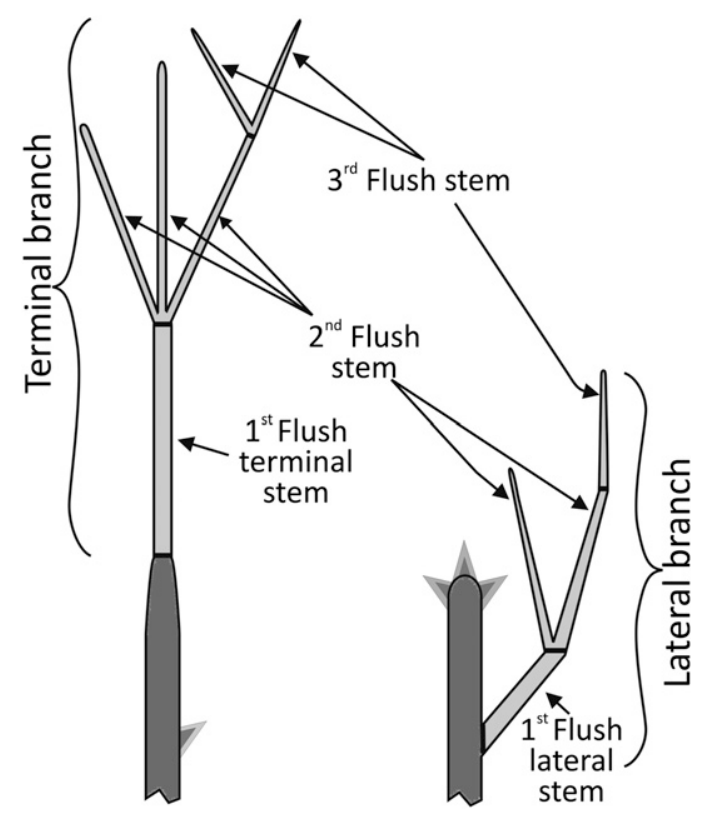

Fig. 7. Diagram showing flushes and branch positions of Ligustrum japonicum.

buds of apple trees (Malus $\times$ domestica), in which lateral buds had fewer leaf primordia and bud scales than terminal buds (Costes, 2003). The factor that signaled shoot apical meristem in determinate stems to start differentiating scales and consequently set a bud was not perceived in indeterminate stems. Causal agents that arrested growth of determinate stems were undetermined. Nutrient availability at the meristematic region may be involved in bud set. Reserve carbohydrates are often used for growth of sprouts and root suckers (Kozlowski, 1992). Moreover, mitotic activity and dormancy were related with carbohydrate levels within the bud of douglas fir [Pseudotsuga menziesii (Owens and Molder, 1973)].

EFFECT OF INTERMITTENT WATER STRESS ON GROWTH. LONg irrigation cycles resulted in shoot dry mass reductions of $\approx 28 \%$ when compared with SC (Silva et al., 2012). Limited substrate

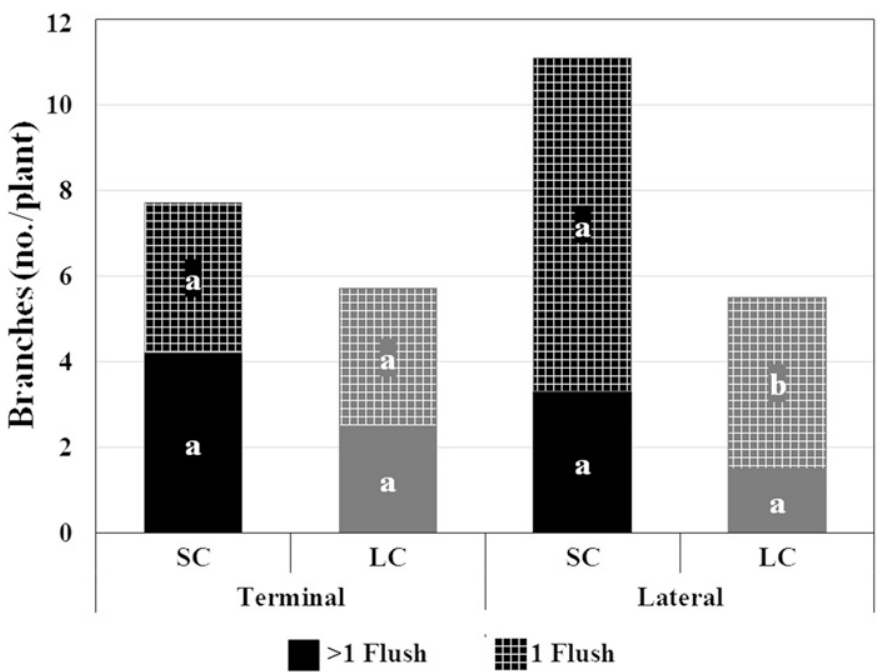

Fig. 8. New branch distribution and number of branches with one or more flushes of growth of Ligustrum japonicum [short irrigation cycle (SC), long irrigation cycle (LC)]. Letters indicate mean separation between treatments by Fisher's least significant difference at $P=0.05$.
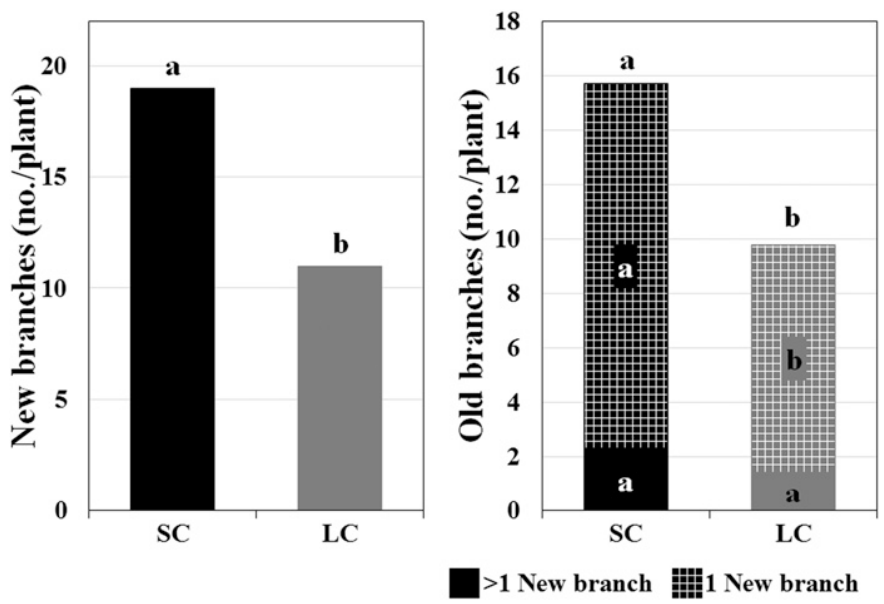

Fig. 9. Total new branches per plant of Ligustrum japonicum and branch generation by old branches [short irrigation cycle (SC), long irrigation cycle (LC)]. Letters indicate mean separation between treatments by Fisher's least significant difference at $P=0.05$.

moisture also reduced several other growth parameters. Number of new branches were reduced $40 \%$ (Figs. 4 and 8), especially lateral branches. Total growing points exhibited a $42 \%$ reduction (Fig. 6), whereas length of new branches declined 22\% (Fig. 9). Plants grown under LC had proportionally more long shoots and growth was sparser (Fig. 4).

Water shortage affected shoot architecture by enhancing apical dominance. Water stress increased terminal bud dominance over the two lateral buds at the apex. Although SC plants had $50 \%$ of terminal buds outgrowing isolated, LC treatment resulted in $68 \%$ of terminal buds outgrowing isolated (Fig. 10). Lateral branching was also affected, declining from an average of 11.1 new lateral branches produced by SC plants to only 5.4 produced by LC plants (Figs. 4 and 8). First-flush determinate lateral branching of SC plants was favored not only in total length [126 vs. $77 \mathrm{~cm}$ for SC and LC, respectively (Fig. 11)], but also in number of stems per plant (Fig. 4). In contrast, LC 


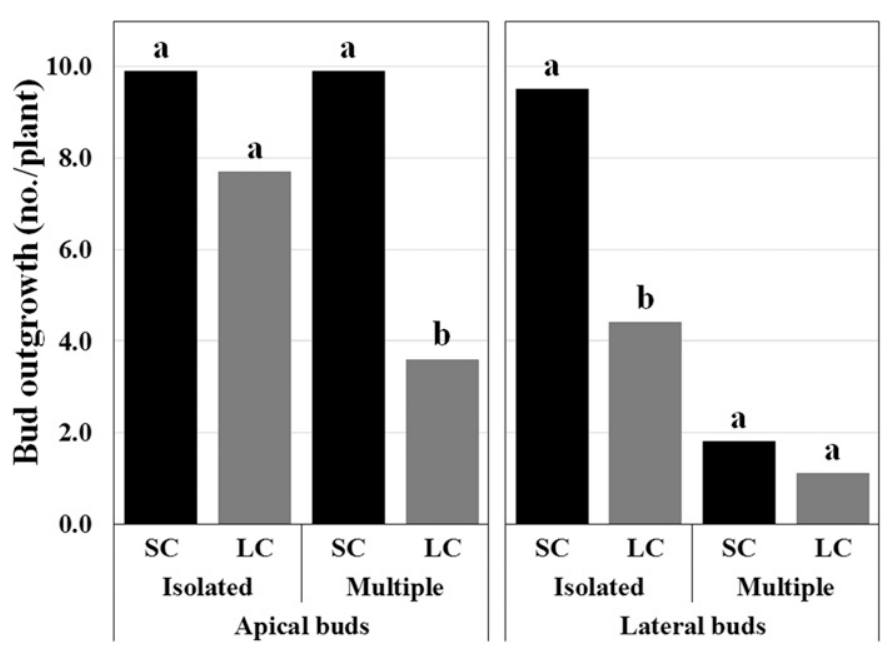

Fig. 10. Bud growth of Ligustrum japonicum-isolated or multiple [short irrigation cycle (SC), long irrigation cycle (LC)]. Letters indicate mean separation between treatments by Fisher's least significant difference at $P=0.05$.

stems tended to have one extra pair of leaves, longer internodes, and longer stem length, suggesting that indeterminate growth may have been triggered initially, but bud water shortage forced bud formation. Neoformation is considered a plastic response of woody plants to factors acting at the time of shoot extension (Guedon et al., 2006). Indeterminate growth was clearly triggered more often in terminal buds of LC plants than in SC plants. Terminal stems of SC plants exhibited mainly determinate growth [103.6 vs. $19.6 \mathrm{~cm}$ average determinate vs. indeterminate growth (Fig. 11)]. In contrast, plants under water shortage had similar total linear determinate and indeterminate growth [74 and $73 \mathrm{~cm}$ (Fig. 11)]. Moreover, the number of indeterminate terminal stems increased to similar levels of indeterminate lateral stems in LC plants (Fig. 4).

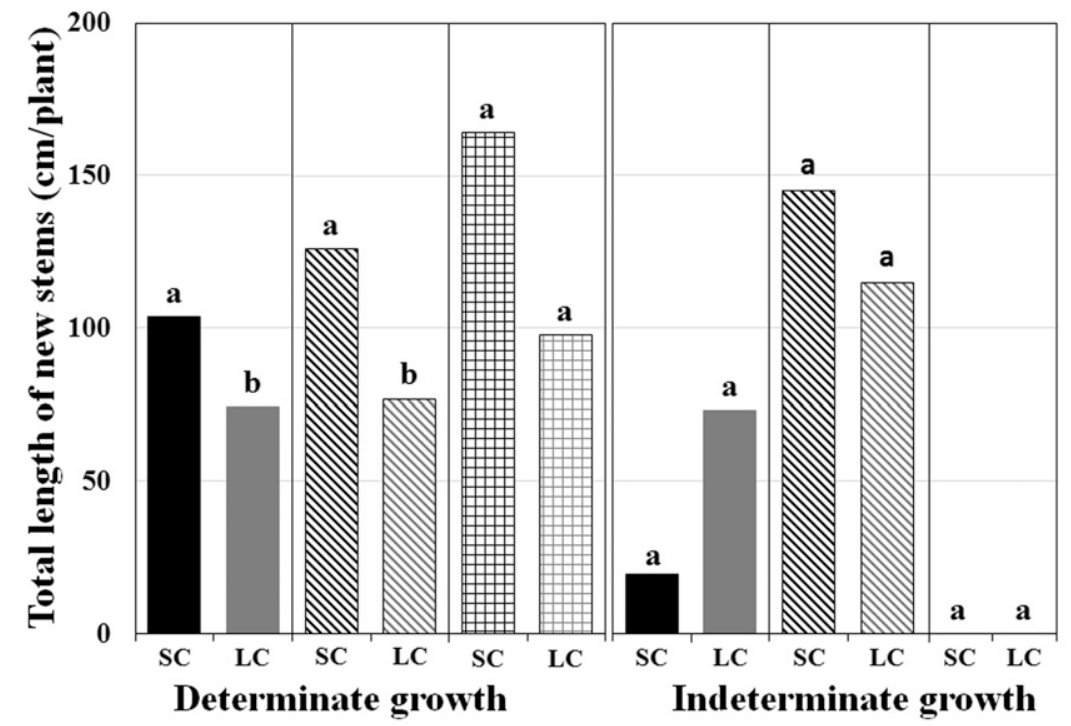

$1^{\text {st }}$ Flush terminal stem $1^{\text {st }}$ Flush lateral stem $2^{\text {nd }}$ and $3^{\text {rd }}$ Flush stems

Fig. 11. Axis formation by different stem types (total length of new branches) of Ligustrum japonicum [short irrigation cycle (SC), long irrigation cycle (LC)]. Letters indicate mean separation between treatments by Fisher's least significant difference at $P=0.05$.
The 7-d wetting and drying cycles changed the morphological and physiological behavior of japanese privet by potentiating apical dominance. The beginning of the first shoot flush coincided with the beginning of the water stress treatment. At subsequent flushes, which occurred later in the water-stressed treatment, old buds burst more frequently than newly formed apex lateral buds. As plants began to adapt to the stress imposed, indeterminate growth was triggered more often in meristematical regions of terminal buds. In contrast, SC plants tended to set a bud and then invest in the production of new leaves in a second flush developing second-flush stems. Conversely, shoot apical meristem of LC plants turned to indeterminate growth, thus producing neoformed leaves.

\section{Conclusions}

Age and position affected japanese privet's bud capacity for outgrowth. The first spring flush was mainly the result of lateral bud outgrowth. This resulted in basal branching, possibly reflecting lateral bud proximity to storage carbohydrates and a postulated root-to-shoot signal in roots (Beveridge, 2000; Waldie et al., 2010) or stored carbohydrates in the trunk (Salaun and Charpentier, 2001). At the second flush of growth, not only lateral buds, but also new buds were able to outgrow, because new leaves could generate carbohydrates to support new bud outgrowth. First-flush terminal stems had mostly determinate growth, whereas first-flush lateral stems had an increased number of stems with indeterminate growth.

Exposure to intermittent water stress such as experienced in natural settings resulted in stronger apical dominance in japanese privet. As a result of prolonged intermittent water stress, bud setting of terminal bud was delayed more often and indeterminate growth was triggered in these shoot tips. Moreover, in the stems that stopped growing at the determinate stage and set a bud, newly formed apex lateral bud outgrew less often, thus suggesting increased apical dominance of terminal bud over apex lateral bud. Further into the treatments, well-irrigated plants tended to invest in the production of new leaves, developing second-flush stems in a new shoot flush. Plants under intermittent water stress continued new leaf production, with indeterminate growth, instead of setting a bud. These plants had fewer but normalsized leaves by the end of the study because they were able to fully expand leaves after a root flush, which resulted in the establishment of a normal balance between absorbing and transpiring surfaces (Silva et al., 2012).

\section{Literature Cited}

Arora, R., L.J. Rowland, and K. Tanino. 2003. Induction and release of bud dormancy in woody perennials: A science comes of age. HortScience 38:911-921.

Beveridge, C.A. 2000. Long-distance signaling and a mutational analysis of branching in pea. Plant Growth Regulat. 32:193-203. 
Borchert, R. 1975. Endogenous shoot growth rhythms and indeterminate shoot growth in oak. Physiol. Plant. 35:152-157.

Buck-Sorlin, G.H. and A.D. Bell. 2000. Crown architecture in Quercus petraea and $Q$. robur: The fate of buds and shoots in relation to age, position and environmental perturbation. Forestry 73:331-349.

Costes, E. 2003. Winter bud content according to position in 3-yearold branching systems of 'Granny Smith' apple. Ann. Bot. (Lond.) 92:581-588.

Frugis, G., D. Giannino, G. Mele, C. Nicolodi, A. Chiappetta, M.B. Bitonti, A.M. Innocenti, W. Dewitte, H. Van Onckelen, and D. Mariotti. 2001. Overexpression of KNAT1 in lettuce shifts leaf determinate growth to a shoot-like indeterminate growth associated with an accumulation of isopentenyl-type cytokinins. Plant Physiol. 126:1370-1380.

Guedon, Y., J.G. Puntieri, S. Sabatier, and D. Barthelemy. 2006. Relative extents of preformation and neoformation in tree shoots: Analysis by a deconvolution method. Ann. Bot. (Lond.) 98:835-844. Hanson, P.J., R.E. Dickson, J.G. Isebrands, T.R. Crow, and R.K. Dixon. 1986. A morphological index of Quercus seedling ontogeny for use in studies of physiology and growth. Tree Physiol. 2:273-281.

Ishii, H. and A. Iwasaki. 2008. Ecological restoration of a fragmented urban shrine forest in southeastern Hyogo prefecture, Japan: Initial effects of the removal of invasive Trachycarpus fortunei. Urban Ecosyst. 11:309-316.

Kerstetter, R.A. and S. Hake. 1997. Shoot meristem formation in vegetative development. Plant Cell 9:1001-1010.

Kozlowski, T.T. 1992. Carbohydrate sources and sinks in woody-plants. Bot. Rev. 58:107-222.

Kuang, J.-B., N.C. Turner, and I.E. Henson. 1990. Influence of xylem water potential on leaf elongation and osmotic adjustment of wheat and lupin. J. Expt. Bot. 41:217-221.

Little, C.H.A. 1970. Apical dominance in long shoots of white pine (Pinus strobus). Can. J. Bot. 48:239-253.

Marcelis-Van Acker, C.A.M. 1994. Development and growth potential of axillary buds in roses as affected by bud age. Ann. Bot. (Lond.) 74:437-443.

Meloche, C.G. and P.K. Diggle. 2003. The pattern of carbon allocation supporting growth of preformed shoot primordia in Acomastylis rossii (Rosaceae). Amer. J. Bot. 90:1313-1320.

Napoli, C.A., C.A. Beveridge, and K.C. Snowden. 1999. Reevaluating concepts of apical dominance and the control of axillary bud outgrowth. Curr. Top. Dev. Biol. 44:127-169.
Nemali, K.S., F. Montesano, S.K. Dove, and M.W. van Iersel. 2007. Calibration and performance of moisture sensors in soilless substrates: $\mathrm{ECH}_{2} \mathrm{O}$ and Theta probes. Sci. Hort. 112:227-234.

Owens, J.N. and M. Molder. 1973. Study of DNA and mitotic activity in vegetative apex of douglas-fir during annual growth cycle. Can. J. Bot. 51:1395-1409.

Puntieri, J.G., J.E. Grosfeld, M. Stecconi, C. Brion, and D. Barthelemy. 2007. Bud and growth-unit structure in seedlings and saplings of Nothofagus alpina (Nothofagaceae). Amer. J. Bot. 94:13821390.

Remphrey, W.R. and G.R. Powell. 1984. Crown architecture of Larix laricina sapling: Shoot preformation and neoformation and their relationship to shoot vigor. Can. J. Bot. 62:2181-2192.

Salaun, M. and S. Charpentier. 2001. Rapid analysis of organic and amino acids by capillary electrophoresis: Application to glutamine and arginine contents in an ornamental shrub. J. Plant Physiol. 158:1381-1386.

Sauter, A., W.J. Davies, and W. Hartung. 2001. The long-distance abscisic acid signal in the droughted plant: The fate of the hormone on its way from root to shoot. J. Expt. Bot. 52:1991-1997.

Silva, D. and R.C. Beeson, Jr. 2011. A large-volume rhizotron for evaluating root growth under natural-like soil moisture conditions. HortScience 46:1677-1682.

Silva, D.D., M.E. Kane, and R.C. Beeson. 2012. Changes in root and shoot growth and biomass partition resulting from different irrigation intervals for Ligustrum japonicum Thunb. HortScience 47:16341640 .

Snowball, A.M. 1997. Seasonal cycle of shoot development in selected Actinidia species. N. Z. J. Crop Hort. Sci. 25:221-231.

Tamura, F., K. Tanabe, and T. Ikeda. 1993. Relationship between intensity of bud dormancy and levels of ABA in japanese pear 'Nilisseiki'. J. Jpn. Soc. Hort. Sci. 62:75-81.

Thomas, R.G. and M.J.M. Hay. 2009. Axillary bud outgrowth potential is determined by parent apical bud activity. J. Expt. Bot. 60:42754285 .

Waldie, T., A. Hayward, and C.A. Beveridge. 2010. Axillary bud outgrowth in herbaceous shoots: How do strigolactones fit into the picture? Plant Mol. Biol. 73:27-36.

Zhang, J.T., C.S. Mu, D.L. Wang, J.F. Wang, and G.X. Chen. 2009. Shoot population recruitment from a bud bank over two seasons of undisturbed growth of Leymus chinensis. Botany-Botanique $87: 1242-1249$. 